\title{
Estudo da viabilidade de utilização de garrafa PET triturada na produção de tijolos
}

\section{ecológicos}

\author{
Feasibility study of using crushed PET bottle in the production of ecological bricks \\ Estudio de viabilidad del uso de botella de PET triturado en la producción de ladrillos ecológicos
}

Recebido: 25/10/2021 | Revisado: 02/11/2021 | Aceito: 05/11/2021 | Publicado: 09/11/2021

\author{
Paulysendra Felipe Silva \\ ORCID: https://orcid.org/0000-0002-0129-8772 \\ Instituto Federal de Educação, Ciência e Tecnologia do Piaú, Brasil \\ E-mail: sendra_102@hotmail.com \\ Rebeka Manuela Lobo Sousa \\ ORCID: https://orcid.org/0000-0002-8195-6447 \\ Instituto Federal de Educação, Ciência e Tecnologia do Piauí, Brasil \\ E-mail:rebekamanuela28@gmail.com \\ Francisca das Chagas Oliveira \\ ORCID: https://orcid.org/0000-0002-6262-9125 \\ Instituto Federal de Educação, Ciência e Tecnologia do Piauí, Brasil \\ E-mail: francisca.mat@ hotmail.com \\ Sávio Torres Melo \\ ORCID: https://orcid.org/0000-0001-6725-1689 \\ Instituto Federal de Educação, Ciência e Tecnologia do Piauí, Brasil \\ E-mail: savio.melo@hotmail.com \\ Heitor Fernandes Sousa \\ ORCID: https://orcid.org/0000-0002-7617-4117 \\ Instituto Federal de Educação, Ciência e Tecnologia do Piauí, Brasil \\ E-mail: heitorfcivil@gmail.com \\ Phillype Dowglas Lopes \\ ORCID: https://orcid.org/0000-0002-4103-3883 \\ Instituto Federal de Educação, Ciência e Tecnologia do Piauí, Brasil \\ E-mail: eng.phillype@ hotmail.com \\ Francisco Arlon De Oliveira Chaves \\ ORCID: https://orcid.org/0000-0002-5503-0923 \\ Centro Universitário Santo Agostinho, Brasil \\ E-mail: arlonoliv@hotmail.com \\ Gilvan Moreira da Paz \\ ORCID: https://orcid.org/0000-0002-6849-0320 \\ Instituto Federal de Educação, Ciência e Tecnologia do Piauí, Brasil \\ E-mail:gilvan@ifpi.edu.br \\ Roberto Arruda Lima Soares \\ ORCID: https://orcid.org/0000-0003-1892-7499 \\ Instituto Federal de Educação, Ciência e Tecnologia do Piaú, Brasil \\ E-mail: robertoarruda@ifpi.edu.br
}

\begin{abstract}
Resumo
A garrafa PET (Polietileno Tereftalato) apresenta diversas utilizações atualmente, desde o armazenamento de bebidas (refrigerante, suco, etc.) até decorações em geral. A importância de realizar a coleta e reciclagem deste material corresponde à diminuição dos impactos ao meio ambiente, pois o mesmo demora muitos anos para decompor, em outras palavras, implementar a sustentabilidade na região. Esta pesquisa pretende analisar o polímero reciclado juntamente ao tijolo solo-cimento mediante a percentuais de substituição deste ao solo, a fim de realizar testes físicoquímicos com a intenção de avaliar a possibilidade do seu uso na construção civil. Para a realização dessa pesquisa foram produzidas amostras, uma com argila pura e outra com adição de garrafa PET triturada. Com esses experimentos será possível verificar a viabilidade da inclusão de PET sem comprometer a resistência mecânica do tijolo ecológico e de forma benéfica ao meio ambiente.
\end{abstract}

Palavras-chave: Cerâmicas; PET; Reciclagem.

\section{Abstract}

The PET bottle (Polyethylene Terephthalate) has several uses today, from the storage of beverages (soft drink, juice, etc.) to decorations in general. The importance of collecting and recycling this material corresponds to the reduction of impacts on the environment, because it takes many years to decomplace, in other words, to implement 
sustainability in the region. This research aims to analyze the recycled polymer together with the soil-cement brick by percentages of soil replacement, in order to perform physical-chemical tests with the intention of evaluating the possibility of its use in civil construction. Samples were produced for this research, one with pure clay and the other with the addition of a crushed PET bottle. With these experiments it will be possible to verify the feasibility of the inclusion of PET without compromising the mechanical resistance of the ecological brick and in a beneficial way to the environment.

Keywords: Ceramics; PET; Recycling.

\section{Resumen}

La botella de PET (tereftalato de polietileno) tiene varios usos en la actualidad, desde el almacenamiento de bebidas (refrescos, jugos, etc.) hasta la decoración en general. La importancia de recolectar y reciclar este material corresponde a la reducción de impactos en el medio ambiente, ya que demora muchos años en descomponerse, es decir, implementar la sustentabilidad en la región. Esta investigación pretende analizar el polímero reciclado junto con el ladrillo suelo-cemento a través del porcentaje de su reposición en el suelo, con el fin de realizar ensayos físicoquímicos con la intención de evaluar la posibilidad de su uso en la construcción civil. Para llevar a cabo esta investigación se elaboraron muestras, una con arcilla pura y la otra con el agregado de una botella de PET triturado. Con estos experimentos se podrá comprobar la viabilidad de incluir PET sin comprometer la resistencia mecánica del ladrillo ecológico y de forma beneficiosa para el medio ambiente.

Palabras clave: Cerámica; PET; Reciclaje.

\section{Introdução}

Como consequência da busca de materiais sustentáveis, foi desenvolvida a tecnologia da fabricação de tijolos ecológicos por volta de 1940 junto ao PCA (Portland Cement Association). No Brasil, somente na década de 1960 as pesquisas começaram a se desenvolver em instituições como: IPT (Instituto de Pesquisas Tecnológicas do Estado de São Paulo) e ABCP (Associação Brasileira de Cimento Portland), a fim de destacar com mais abrangência o manuseio desses tijolos perante as construções, desenvolvendo futuramente a sua aplicação (Biobloc,2015). De acordo com Grande (2003), os tijolos de solocimento representam uma alternativa em plena sintonia com as diretrizes do desenvolvimento sustentável, pois requerem baixo consumo de energia na extração da matéria-prima, dispensam o processo de queima e reduzem a necessidade de transporte, uma vez que os tijolos podem ser produzidos com solo do próprio local da obra

Segundo a NBR 8491 ABNT. (2012), o tijolo de solo-cimento se trata de um componente de alvenaria cuja composição é de solo (o qual não deve apresentar matéria orgânica em teores prejudiciais as suas propriedades), cimento Portland, água e aditivos, gerando dessa forma uma mistura homogênea, compactada e endurecida. Esse tipo de tijolo pode ser maciço ou vazado.

O tijolo de solo-cimento também recebe a nomenclatura de tijolo ecológico, pois durante sua fabricação não necessita queima, evitando dessa forma a emissão de gases de efeito estufa, portanto contribui de forma positiva ao funcionamento do ecossistema. Ainda no quesito ambiental o tijolo ecológico apresenta em sua composição um dos elementos mais abundantes no planeta Terra, que é o solo, e podendo ser adicionado em sua composição alguns resíduos de construção civil favorecendo assim a sustentabilidade (Weber et al., 2017).

A incorporação de aditivos ou resíduos em tijolos solo-cimento já vem sendo empregado em pesquisas cientificas, obtendo-se resultados satisfatórios e positivos em relação às propriedades tecnológicas sem contar com os benefícios que podem ser obtidos em termos de preservação ambiental (Carvalho, 2019). Em busca de alternativas capazes de satisfazer um sistema sustentável, na fabricação dos tijolos ecológicos ou solo-cimento, tem-se a alternativa de reduzir os impactos ambientais ocasionados devido a sua matéria prima em abundância, o solo (Dantas, 2015).

O PET é um tipo de poliéster amplamente utilizado para a fabricação de engarrafados porque, na década de 1970 , surgiu a necessidade da produção de garrafas maiores, de peso leve e inquebráveis para armazenar bebidas gaseificadas. As características do PET estão relacionadas com sua transparência e resistência ao desgaste e à corrosão. Possui acabamento de alta resistência e suave, o que explica sua ampla utilização em garrafas de água mineral, refrigerantes, sucos, óleos 
comestíveis, produtos farmacêuticos entre outros. São as embalagens pós-consumo do PET - Poli (Tereftalato de Etileno), resíduos que estão atingindo percentuais cada vez maiores na composição do lixo urbano, com presença crescente no meio ambiente (ABIPET, 2012).

De acordo com Frigione (2010) a reciclagem do PET proporciona vantagens nas dimensões ambiental, social e econômica. Estas vantagens se traduzem através da diminuição da extração de matéria prima virgem não renovável, na disposição em aterros, no consumo de energia, pois no processo de reciclagem é utilizada em média $30 \%$ da energia necessária para produzir a resina virgem sem comprometer a qualidade do produto final, na criação de uma cadeia de logística para coletar, segregar, transportar e destinar este rejeito e na redução do preço dos produtos na utilização do material reciclado (algo em torno de $30 \%$ em comparação ao produto virgem).

Este trabalho busca por alternativas que minimizem a degradação do meio ambiente provocada pelo descarte de plásticos, visando proporcionar soluções ecologicamente corretas caracterizando e avaliando o grau de confiabilidade dos materiais utilizados na produção de tijolos ecológicos. Desta forma, entende-se que a substituição de parte da argila por resíduos de PET para a produção de tijolos ecológicos possa apresentar uma alternativa sustentável para a reciclagem de resíduos PET.

\section{Revisão Bibliográfica}

\subsection{Tijolo solo-cimento}

Mazzeo (2003) afirma que, na produção do tijolo solo cimento prensado equivale às etapas de preparação do solo, o preparo da mistura, a moldagem dos tijolos e os processos de cura e armazenamento. Com relação à escolha do traço do tijolo, leva-se em conta aquele que apresentar menor consumo de cimento, atendendo assim aos critérios estabelecidos na norma NBR 8491 (critérios de compressão e absorção de água).

Conforme Vieira et al. (2007) o tijolo de solo-cimento apresenta diversas vantagens como boa durabilidade, boa resistência à compressão, fases lisas e regulares, economia de tempo na execução da obra, economia de matéria, além de conforto térmico e acústico para a residência.

O tijolo de solo-cimento apresenta dois furos no seu corpo e saliências. O sistema de construção da alvenaria com esse material é baseado no intertravamento e encaixe dos blocos, sendo este permitido pelo conjunto de saliências e rebaixos no topo e na base do bloco, garantindo também o seu auto alinhamento (Pecoriello, 2003).

Esses tipos de tijolo são encontrados em variados tamanhos e modelos (Quadro 1), sendo que sua escolha é feita de acordo com o projeto a ser executado. Apresentam-se maciços ou furados, e com ou sem canaleta. Durante o processo de execução deve-se atender a muitos detalhes para que a qualidade desejada dos tijolos seja alcançada, e o resultado final conclua-se em um componente para alvenarias com menor impacto ambiental que os tradicionais (Pisani, 2005). 
Quadro 1. Tipos de tijolo ecológico produzidos e comercializados.

\begin{tabular}{|l|c|l|}
\hline Tipo & Dimensões & Características \\
\hline Maciço comum & $\begin{array}{c}5 \times 10 \times 20 \mathrm{~cm} . \\
5 \times 10 \times 21 \mathrm{~cm} .\end{array}$ & $\begin{array}{l}\text { Assentamento com consumo de argamassa similar dos } \\
\text { tijolos maciços comuns. }\end{array}$ \\
\hline $\begin{array}{l}\text { Tijolo Maciço } \\
\text { com encaixes }\end{array}$ & $\begin{array}{l}5 \times 10 \times 21 \mathrm{~cm} . \\
5 \times 11 \times 23 \mathrm{~cm} .\end{array}$ & $\begin{array}{l}\text { Assentamento com encaixes com baixo consumo de } \\
\text { argamassa. }\end{array}$ \\
\hline $\begin{array}{l}\text { 1/2 Tijolo } \\
\text { com encaixes }\end{array}$ & $\begin{array}{c}5 \times 10 \times 10,5 \mathrm{~cm} . \\
5 \times 11 \times 11,5 \mathrm{~cm} .\end{array}$ & $\begin{array}{l}\text { Elemento produzido para que não haja quebras na } \\
\text { formação dos aparelhos com juntas desencontradas. }\end{array}$ \\
\hline $\begin{array}{l}\text { Tijolos com dois } \\
\text { furos e encaixes }\end{array}$ & $\begin{array}{c}5 \times 10 \times 20 \mathrm{~cm} . \\
7,5 \times 12,5 \times 25 \mathrm{~cm} .\end{array}$ & $\begin{array}{l}\text { Assentamento a seco, com cola branca ou argamassa bem } \\
\text { plástica. Tubulações passam pelos furos verticais. }\end{array}$ \\
\hline $\begin{array}{l}\text { 1/2 tijolo com } \\
\text { furo } \\
\text { encaixe }\end{array}$ & $\begin{array}{c}5 \times 10 \times 10 \mathrm{~cm} . \\
6,25 \times 12,5 \times 12,5 \mathrm{~cm} . \\
7,5 \times 15 \times 15 \mathrm{~cm} .\end{array}$ & $\begin{array}{l}\text { Elemento produzido para acertar os aparelhos, sem a } \\
\text { necessidade de quebras. }\end{array}$ \\
\hline $\begin{array}{l}5 \times 10 \times 20 \mathrm{~cm} . \\
6,25 \times 12,5 \times 25 \mathrm{~cm} . \\
7,5 \times 15 \times 30 \mathrm{~cm} .\end{array}$ & $\begin{array}{l}\text { Elemento empregado para execução de vergas, reforços } \\
\text { estruturais, cintas de amarração e passagens de } \\
\text { tubulações horizontais. }\end{array}$ \\
\hline
\end{tabular}

Fonte: Extraído de Pisani (2005).

\subsection{Solo}

O solo é de grande importância dentro da construção civil, pois é um material de fácil extração e de elaboração simples, podendo em muitos casos ser usado em sua forma bruta ou com adição e mistura manual de materiais que proporcionem ou não maior rigidez. São exemplos comuns do uso do solo laterítico a fabricação de materiais cerâmicos como tijolos e telhas ou mesmo para a construção de base em pavimentação (Nascimento, 2011).

Segundo Pinto (1998), os solos podem ser definidos por um conjunto de partículas sólidas provenientes da desagregação de rochas por ações físicas e químicas.

De acordo com Grande (2003), para se obter um solo-cimento de qualidade se torna necessário conhecer bem o material de origem ao qual se está trabalhando, nesse caso, o solo. O solo deve ser de tal maneira que confira elevada resistência à compressão a material e pequena contração durante a secagem, fatores estes que dependem diretamente de uma mistura equilibrada de areia, silte e argila.

De acordo com Pisani (2005), pode-se acrescentar que, o tijolo de solo cimento possui matéria-prima abundante em todo o planeta por se tratar da terra crua. A NBR 10833:2012, que trata da fabricação de tijolo de solo-cimento com a utilização de prensa manual ou hidráulica - procedimento, recomenda-se os valores apresentados na Tabela 1, para as principais características que o solo deve possuir (ABNT, 2012). 
Tabela 1- Especificação do solo para produção do tijolo ecológico- NBR 10832/13.

\begin{tabular}{lc}
\hline \multicolumn{1}{c}{ Características } & Condições \\
\hline$\%$ do solo que passa na peneira ABNT 4,8 mm (n. $\left.{ }^{\circ} 4\right)$ & $100 \%$ \\
\hline$\%$ do solo que passa na peneira ABNT $0,075 \mathrm{~mm}\left(\mathrm{n}^{\circ} \stackrel{\mathrm{o}}{200)}\right.$ & 10 a $50 \%$ \\
\hline Limite de liquidez & $\leq 45 \%$ \\
\hline Indice de plasticidade & $\leq 18 \%$ \\
\hline
\end{tabular}

Fonte: Adaptado de NBR 10832 (1989/2013).

O solo a ser utilizado na produção dos tijolos de solo-cimento, segundo Pecoriello (2003) deve ser submetido previamente à secagem ao ar em local coberto, atingindo ao final uma umidade homogênea, em seguida deve ser destorroado, e por fim é necessário peneirar o solo para eliminar as partículas com diâmetros superiores a 4.8 mm. Após o peneiramento o solo deve ser bem misturado.

\subsection{PET}

Os resíduos sólidos urbanos (RSU), nos termos da Lei Federal n ${ }^{\circ}$ 12.305/10 ao qual instaurou a Política Nacional de Resíduos Sólidos, compreendendo os resíduos domésticos, assim, todo resíduo que tiver origem de atividades domiciliares provindas de residências e limpeza urbana, tal qual, decorrentes das coletas públicas e particulares ao qual se acumula resíduos (ABRELPE, 2013). Um dos problemas ambientais das cidades contemporâneas é a geração excessiva de resíduos sólidos urbanos (RSU), as sobras das civilizações, o lixo, os restos orgânicos das cozinhas, as embalagens que envolvem os produtos consumidos no dia-a-dia, o desperdício, os pneus, as garrafas, as latas de refrigerante, o papel, as toneladas de resíduos gerados pelos milhões de pessoas que moram nas grandes cidades (Azevedo, 2011).

Com o uso em grande escala das garrafas PET, principalmente a partir da década de 1990, um problema ambiental sério surgiu: muitas destas garrafas eram descartadas de forma incorreta e acabavam parando em terrenos, rios, esgotos, mares e matas. Só que este material pode demorar até 800 anos para se decompor (daí a importância de sua coleta e reciclagem). Uma simples garrafa PET pode ser considerada resíduo sólido caso seja inviável a sua transformação física, físico-química ou biológica, dado a criação de novos serviços e produtos (reciclagem), seja pelo custo da coleta seletiva ou até pela inviabilidade na comercialização desta cadeia por não possuir mercado consumidor desta matéria-prima nas proximidades Moreira. (2013).

A chegada da embalagem de PET no Brasil ocorreu em 1988, trazendo inúmeras vantagens ao consumidor, trouxe também o desafio de sua reciclagem. Nos últimos tempos, a produção nacional de PET vem crescendo. O Brasil é hoje o terceiro maior consumidor mundial de PET para produção de garrafas no mundo, contando com cerca de 3400 marcas de refrigerantes diferentes registradas. Embora pareça que a tendência de crescimento do mercado de embalagens para refrigerantes esteja chegando ao limite, o crescimento do consumo aparente de PET no Brasil aumenta mais rapidamente que a produção, puxado pela entrada do plástico em novos segmentos alimentícios (Dias \& Teodosio, 2006).

\section{Metodologia}

A pesquisa de campo é uma fase que é realizada após o estudo bibliográfico, para que o pesquisador tenha um bom conhecimento sobre o assunto, pois é nesta etapa que ele vai definir os objetivos da pesquisa, as hipóteses, definir qual é o meio de coleta de dados, as amostras e como serão analisadas (Marconi \& Lakatos, 2016). A metodologia de trabalho consistiu na caracterização dos materiais em estudo e determinação dos parâmetros de resistência à compressão e absorção de água dos corpos de prova produzidos. Foram realizados ensaios no laboratório do PPGEM - IFPI e UNIFAPI para a caracterização dos 
solos, os resíduos de PET foram triturados em multiprocessador industrial para adição dos traços dos corpos de prova e para produzir os corpos de provas.

\subsection{Granulometria da argila}

A análise granulométrica dos solos determina a distribuição das dimensões dos grãos de um solo. Esse ensaio é realizado segundo a norma 7181:2016, onde será verificado a granulometria por peneiramento para grãos de até 0,075mm de diâmetro. Esse ensaio foi realizado no laboratório de materiais da AESPI/UNIFAPI.

- Equipamentos necessários: Estufa; Balança de precisão; Recipientes adequados para comportar as amostras; Peneiras de que variam de $4,8 \mathrm{~mm}$ a $0,075 \mathrm{~mm}$; Escova com cerdas metálicas, a ser utilizado para remover os grãos retidos nas malhas das peneiras; Agitador mecânico de peneiras, com dispositivo para fixação de até 6 peneiras, inclusive tampa e fundo; Cápsulas metálicas para determinação do teor de umidade.

Procedimentos do ensaio de laboratório: Determinar a massa da amostra seca em temperatura ambiente (MT), para assim passar o material na peneira de 2,0 mm, lembrando de desmanchar no almofariz todos os torrões, assim garantindo a retenção na peneira somente os grãos maiores que a abertura da malha. Diante disso, lavar a parte retirada na peneira de $2,0 \mathrm{~mm}$ para retirar o excesso de silte ou argila, e em seguida secar em estufa a $105^{\circ} \mathrm{C}$ ou $110^{\circ} \mathrm{C}$. O Material obtido será usado no peneiramento grosso. Do material passado na peneira de 2,0mm tomar cerca de $100 \mathrm{~g}$ para determinação da umidade higroscópica (w), de acordo com a ABNT NBR 6457. Com 100g da amostra em mãos deverá ser feito uma lavagem na peneira de $0,075 \mathrm{~mm}$ o material obtido, vertendo-se água potável à baixa pressão. O material assim obtido é usado no peneiramento fino.

\subsection{Análise da Plasticidade}

Outro ensaio importante para caracterizar o solo é quanto a sua plasticidade e limite de liquidez. O limite de liquidez é o teor em água acima do qual os solos iriam apresentar comportamento de líquido e o limite de plasticidade é o teor de umidade abaixo do qual o solo do estado plástico passa para o estado semissólido perdendo sua capacidade de ser moldado e tornandose quebradiço (Gregorio, 2012). A obtenção do índice de plasticidade da argila permitiu estimar suas propriedades. Para a realização dessa análise usou-se o aparelho casa grande, conforme Figura 1:

Figura 1 - Aparelho casa grande usado na análise da plasticidade.

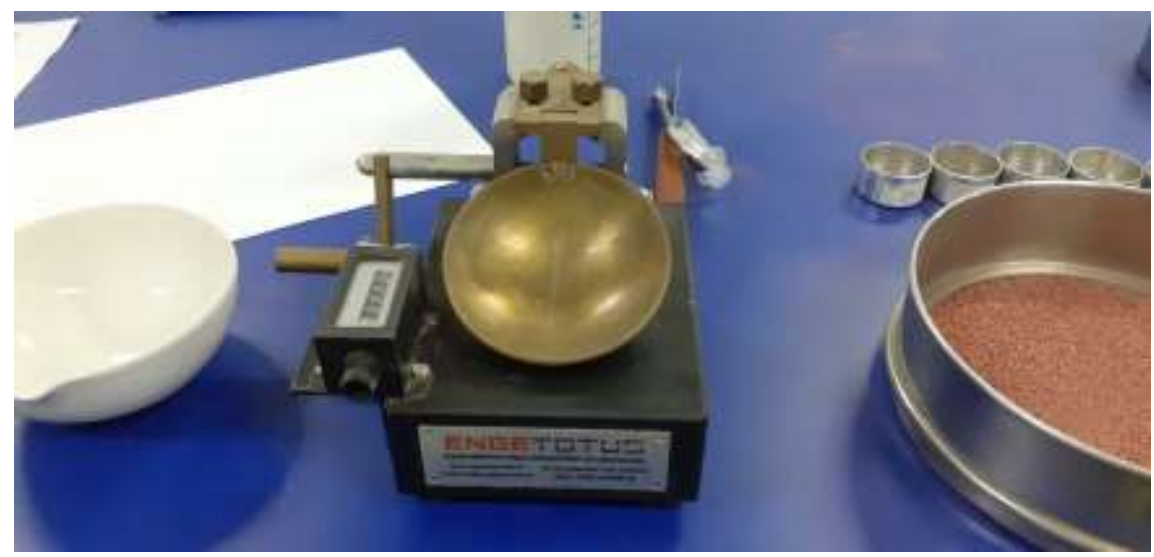

Fonte: Autor (2021). 
O índice de plasticidade, foi determinado de acordo com a norma técnica NBR-6459/84 e NBR 7180/84 da ABNT. Que estabelece que o índice de plasticidade deva ser menor ou igual a 18\% para o tijolo solo cimento.

\subsection{FRX da argila}

A fluorescência de raio-X (FRX) realizou-se no laboratório de materiais no IFPI (Figura 2), através da técnica de espectrometria de fluorescência de raio-X. Essa técnica é utilizada para poder determinar quais são os elementos químicos presentes no solo utilizado. Para uso no equipamento, a amostra deve ter granulometria inferior a $0,075 \mathrm{~mm}$, ou seja, o material a ser utilizado deve ser peneirado anteriormente na peneira 200.

Figura 2 - Preparação para ensaio de FRX.

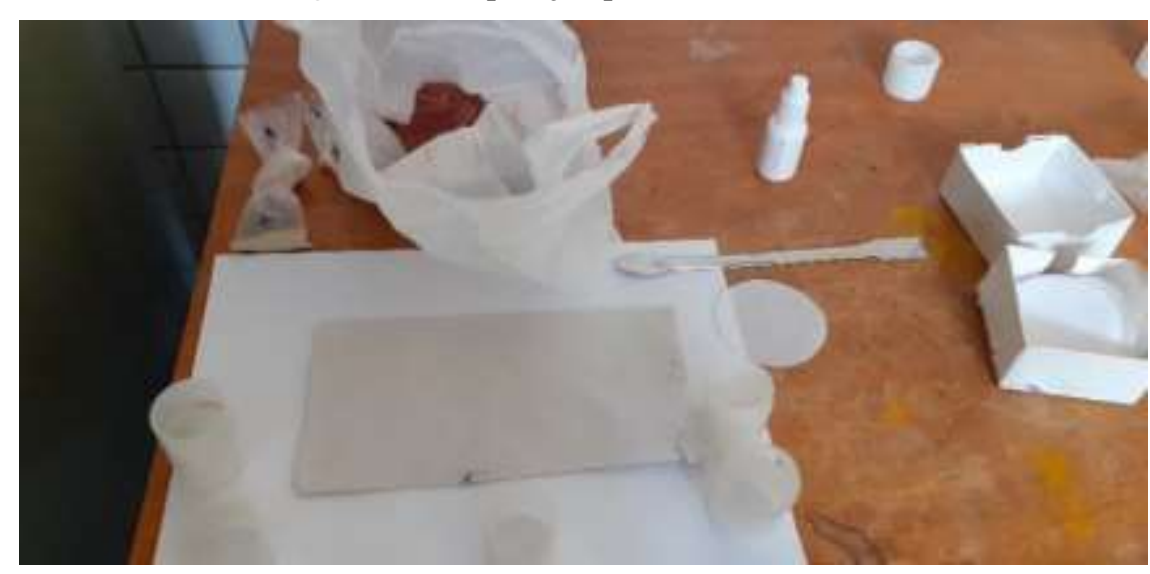

Fonte: Autor (2021).

\subsection{Coleta das embalagens de PET}

As embalagens de refrigerantes foram coletadas na empresa coletora de lixo ETURB e acondicionadas no laboratório de Química (PPGEM). Em seguida foi efetuado a lavagem dos frascos com água e detergente biodegradável com a finalidade de se retirar o máximo possível do resquício de refrigerante que porventura ainda estivesse aderido em suas paredes conforme. Na sequência, foi retirado o rótulo e o gargalo. As embalagens foram preparadas para o corte em pequenos pellets (Figura 4) para futura moldagem dos corpos de prova. Nesta fase de preparação, foi utilizado o triturador industrial, depois que a embalagens foram colocadas para secar ao sol, com os pellets secos, deu-se início a confecção dos corpos de prova.

Figura 3 - Corte de embalagens em pequenos pellets

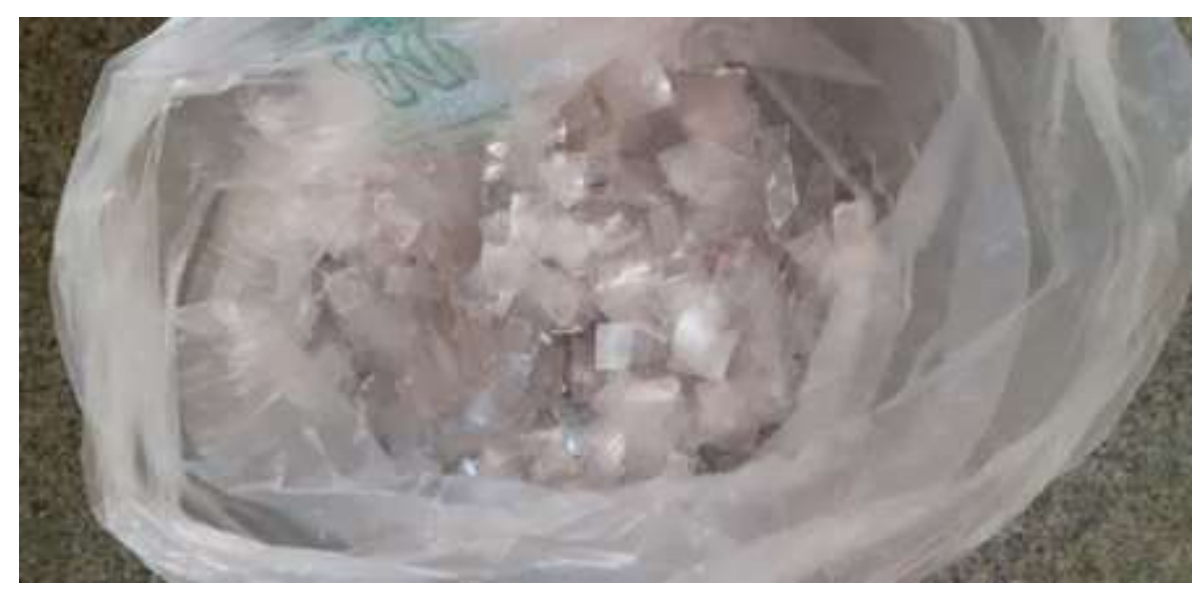

Fonte: Autor (2021). 


\subsection{Formulação dos Traços e Confecção dos corpos de prova}

Para o traço (Figura 4), foi iniciado os ensaios com o traço padrão de solo, cimento e água, que é 1:10 (uma parte de cimento para 10 partes de argila), foi usado para o traço padrão $300 \mathrm{~g}$ de cimento: $3.000 \mathrm{~g}$ de solo e $231 \mathrm{~g}$ de água, o total de PET triturado foi 300g. Posteriormente foram realizados traços substituindo em partes o solo por 20\% de resíduos de PET (300g de cimento, $2.940 \mathrm{~g}$ de solo, $60 \mathrm{~g}$ de PET e $231 \mathrm{~g}$ de água), $30 \%$ de resíduos de PET (300g de cimento, $2.850 \mathrm{~g}$ de solo, $90 \mathrm{~g}$ de PET e $231 \mathrm{~g}$ de água) e $50 \%$ de resíduos de PET (300g de cimento, $2.670 \mathrm{~g}$ de solo, $150 \mathrm{~g}$ de PET e $231 \mathrm{~g}$ de água). Assim, foi averiguado o traço ideal para sua utilização.

Para a confecção dos corpos de prova foi utilizado a norma NBR 8492 (2012) e NBR 10833 (2012), onde deverá ser feito 10 corpos de prova (no mínimo) para cada formulação definida. A mistura será feita de forma manual. Os tijolos serão feitos por meio de prensa (hidráulica ou manual). Após a fabricação, as peças produzidas (Figura 5). deverão ser armazenadas em um local protegido do sol e do vento, e deve-se ter um cuidado com relação ao processo de cura.

Figura 4 - Preparação dos traços.

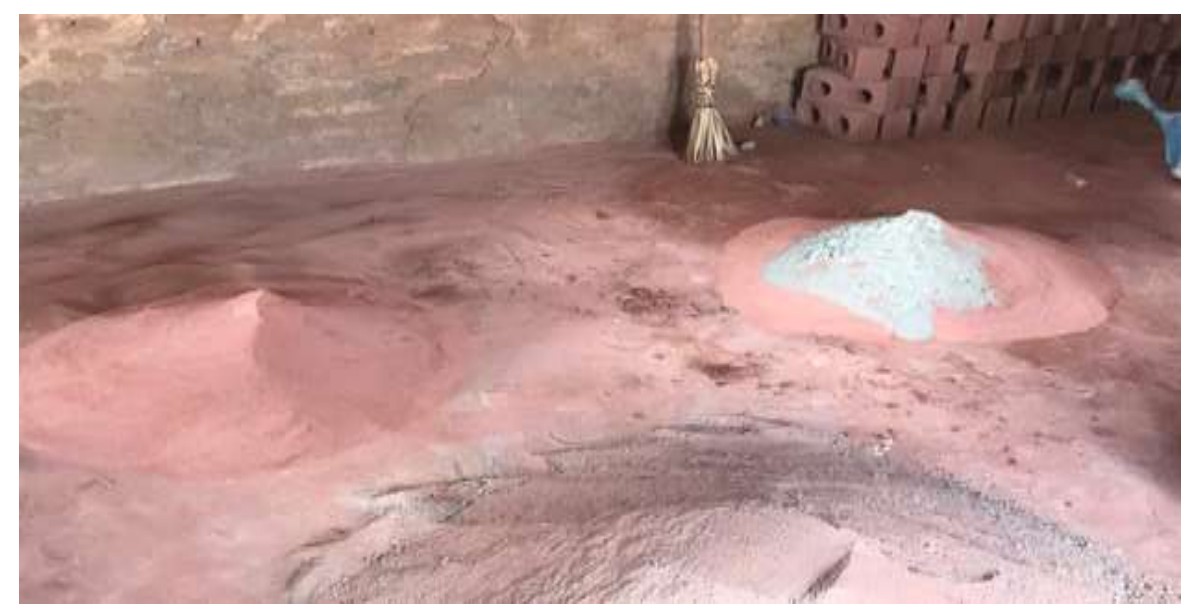

Fonte: Autor (2021).

Figura 5 - Preparação dos corpos de prova.

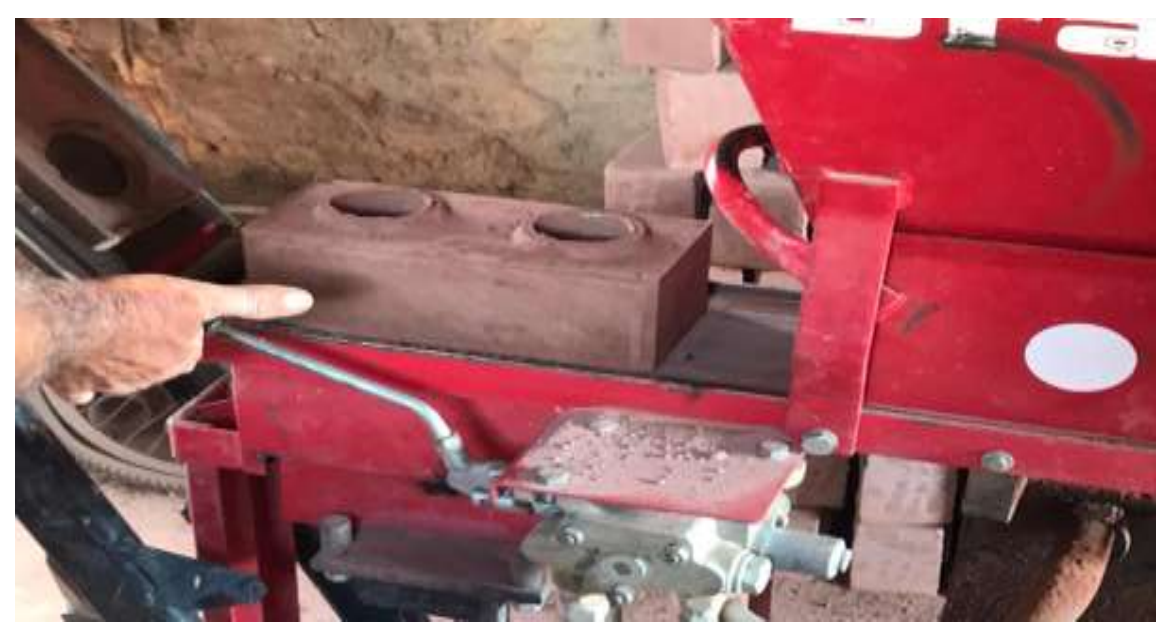

Fonte: Autor (2021).

\subsection{Processo de cura}

A cura do Tijolo Ecológico é um procedimento que visa melhorar o seu processo de endurecimento deixando-o mais resistente e firme. O objetivo é retardar a evaporação da água usada no preparo da mistura, garantindo a completa hidratação 
do cimento e as reações químicas necessárias entre todos os componentes. Ainda de acordo com a ABNT NBR 10833/2012, após a moldagem (Figura 6) e durante os sete primeiros dias, os tijolos devem ser umedecidos, a fim de garantir a cura necessária. E os tijolos, podem ser utilizados após 14 dias de sua fabricação. Os corpos de prova produzidos nos três primeiros dias de cura foram pulverizados com água, duas a quatro vezes por dia. De acordo com Pisani (2015), a cada dia a mais de cura, o tijolo apresenta resistência maior, sendo que após vinte e oito dias a cura está completa e o bloco apresenta aproximadamente 95\% da sua resistência de cálculo, sendo esse o prazo ideal para transporte e utilização. Após o processo de cura ser concluído, o processo de fabricação é encerrado. Para este trabalho foi observado o tempo de cura até os 56 dias que de acordo com Ferreira (2003) estudou a resistência do tijolo ecológico analisando um maior período de cura apresentou resultados significativos, verificando sua influência no resultado da resistência dos corpos de prova.

Figura 6 - Início do processo de cura.

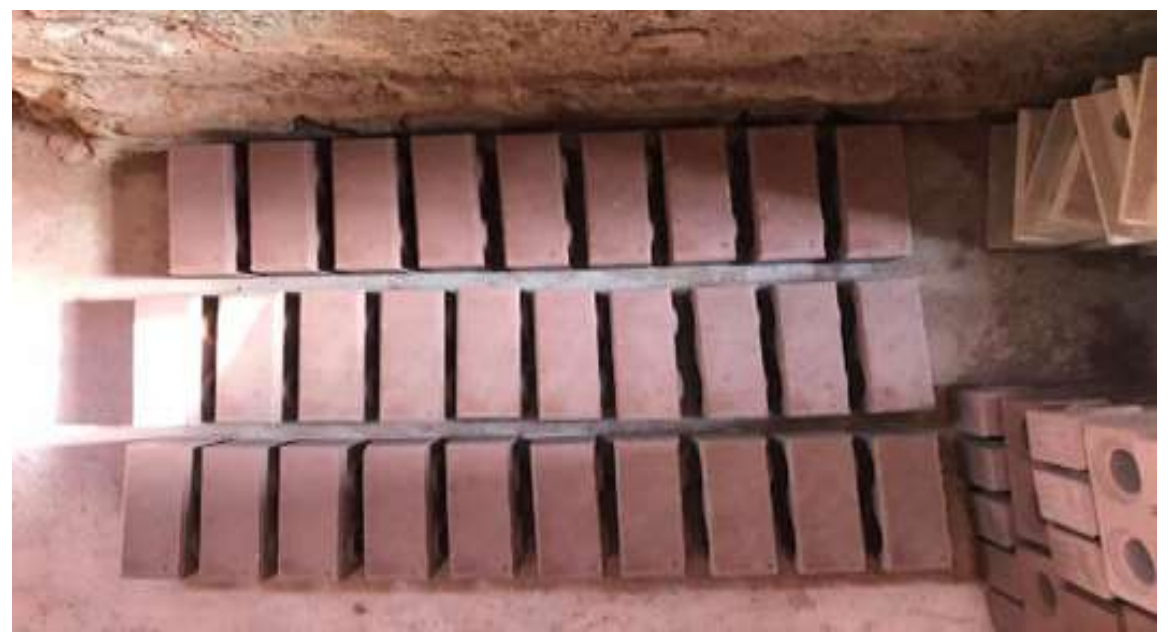

Fonte: Autor (2021).

\subsection{Ensaios de Compactação}

A umidade ótima (Figura 7) e um parâmetro importante para trabalhos realizados com solos, pois propicia condições melhores de trabalhabilidade e máxima compactação do material, proporcionando maiores valores de densidade, resistência e durabilidade, ensaios foram realizados de acordo com a NBR 12023/92.

Figura 7 - Preparação da mistura para ensaio de compactação.

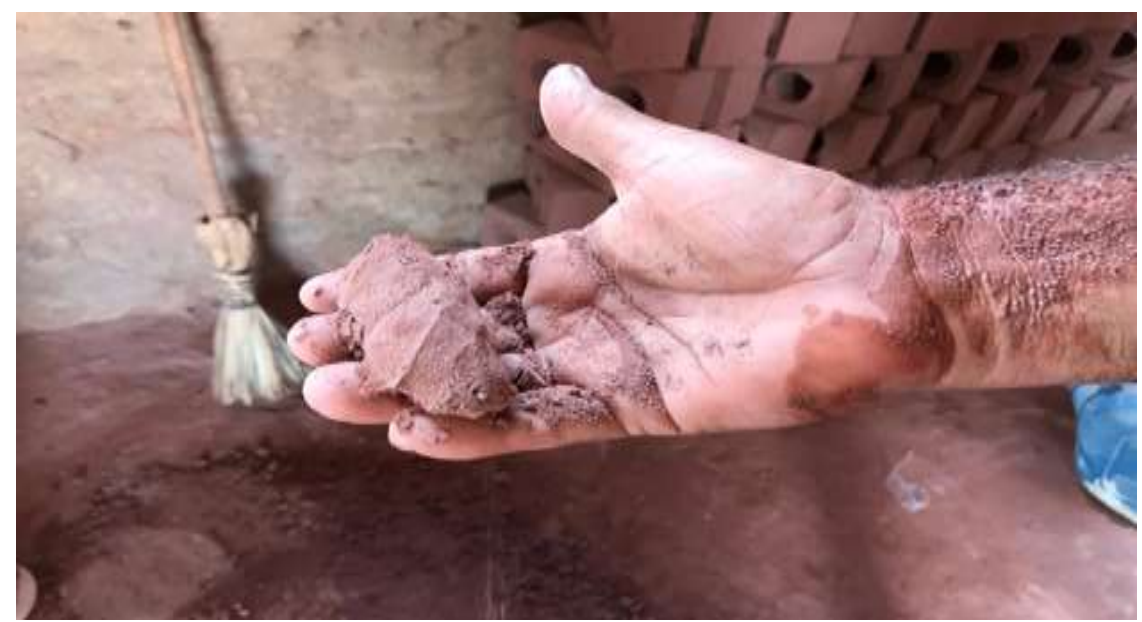

Fonte: Autor (2021). 


\subsection{Absorção de água}

Para esse ensaio deverá ser utilizado 3 corpos de prova de cada formulação. Esses corpos de prova deverão secar em estufa entre $105^{\circ} \mathrm{C} \mathrm{a} 110^{\circ} \mathrm{C}$, e pesados (Figura 8) em seguida, obtendo a massa do corpo de prova seca em gramas (g). Próximo passo do ensaio é imergir os corpos de prova em um tanque (Figura 9) durante 24h, após retirar da água, enxugar superficialmente com um pano levemente umedecido e pesar obtendo assim a massa do corpo de prova saturado em gramas. A amostra ensaiada de acordo com a ABNT NBR 8492 (2012) não pode apresentar a média dos valores de absorção de água maior do que $20 \%$ nem de valores individuais superiores a $22 \%$, com idade mínima de sete dias.

Figura 8 - Peso seco do corpo de prova.

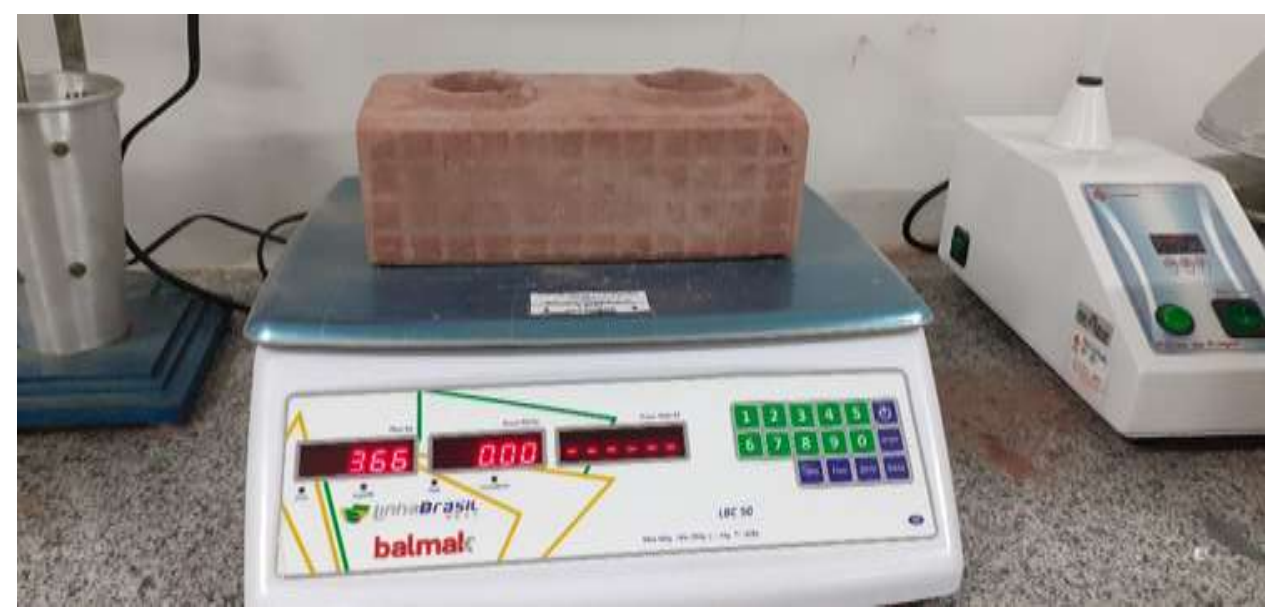

Fonte: Autor (2021).

Figura 9 - corpos de prova imerso em tanque.

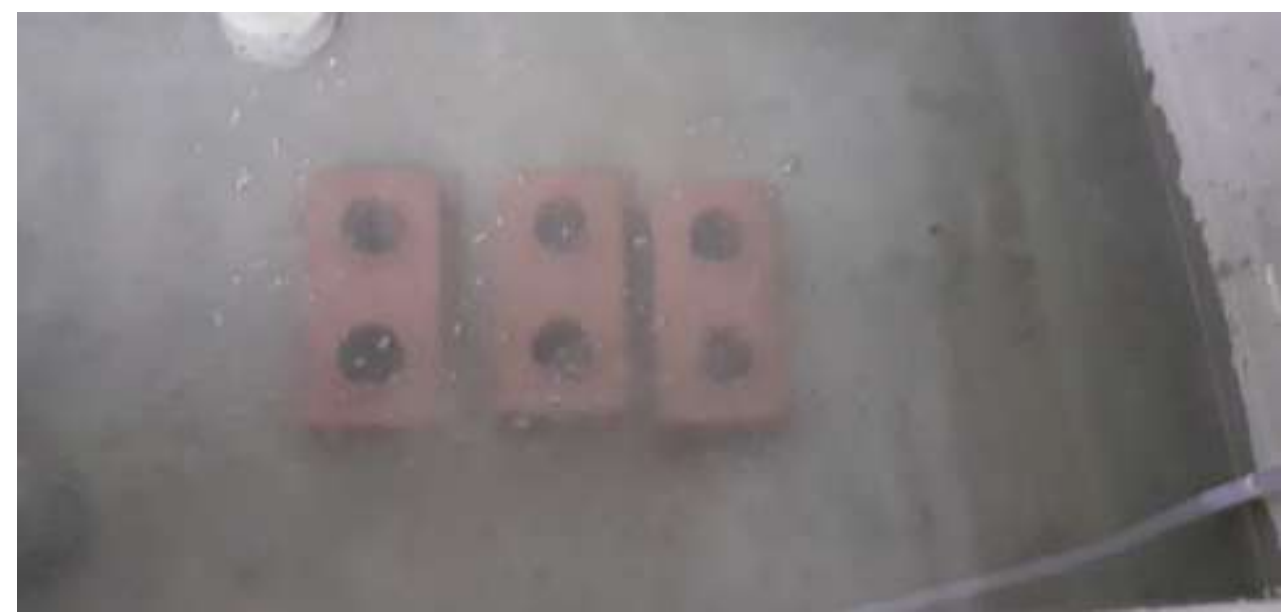

Fonte: Autor (2021).

\subsection{Ensaio de resistência à flexão}

Para a realização do ensaio de compactação foram utilizados 7 corpos de prova para cada traço, conforme recomenda a norma. Os corpos de prova foram colocados sobre duas chapas de ferro (Figura 10) para distribuir melhor a força aplicada pela prensa, como indica a Figura 10. 
Figura 10 - corpo de prova colocados sobre duas chapas de ferro.

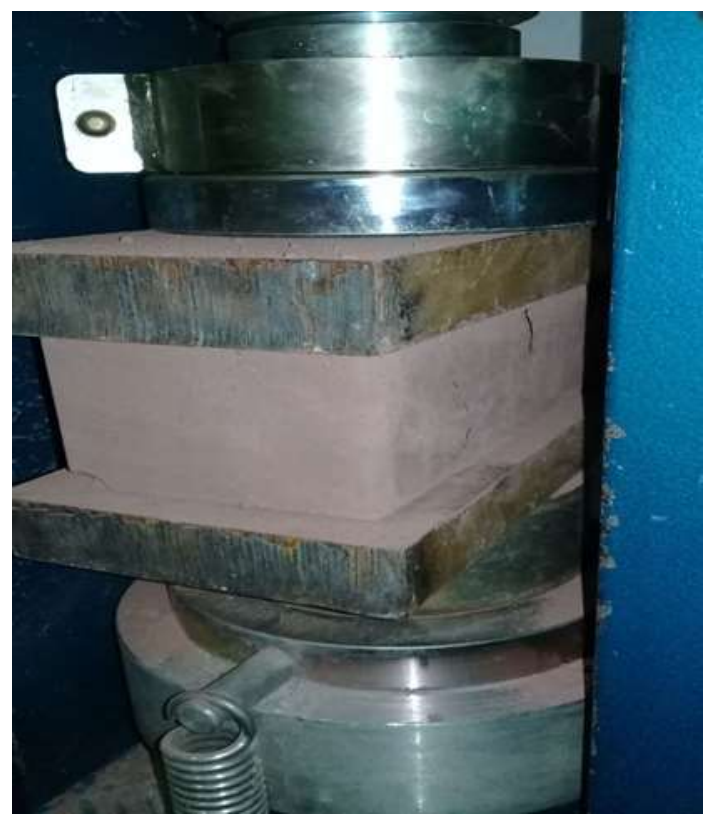

Fonte: Autor (2021).

\section{Resultados e Discussão}

\subsection{Granulometria da argila}

O resultado do ensaio de granulometria está definido no Quadro 2 e Gráfico 1.

Quadro 2 - Ensaio de granulometria da argila.

\begin{tabular}{|l|l|}
\hline Peneira & Passando \\
\hline $2^{\prime \prime}$ & 100,0 \\
\hline $11 / 2 "$ & 100,0 \\
\hline $1 "$ & 100,0 \\
\hline $3 / 4 "$ & 100,0 \\
\hline $3 / 8^{\prime \prime}$ & 100,0 \\
\hline$n^{\circ} 4$ & 100,0 \\
\hline$n^{\circ} 10$ & 100,0 \\
\hline$n^{\circ} 16$ & 99,9 \\
\hline$n^{\mathbf{o}} 30$ & 99,3 \\
\hline$n^{\circ} 40$ & 97,5 \\
\hline$n^{\circ} 50$ & 87,5 \\
\hline$n^{\circ} 100$ & 58,6 \\
\hline$n^{\circ} 200$ & 23,6 \\
\hline
\end{tabular}

Fonte: Autor (2021). 
Gráfico 1 - Curva granulométrica da argila.



Fonte: Autor (2021).

Nota-se no Quadro 2 e Gráfico 1 que representa o gráfico da curva granulométrica observa-se que o material que passa na peneira $\mathrm{n}^{\circ} 4(4,8 \mathrm{~mm})$ corresponde a $100 \%$ do solo e o material que passa na peneira com abertura de malha de 0,075 mm, portanto, dentro do limite entre $10 \%$ e 50\%. Portanto, essa caracterização qualifica esse solo para a produção do tijolo ecológico, conforme critérios estabelecidos pela norma NBR 10832/13.

\subsection{Análise da Plasticidade}

A Tabela 2 contém os limites de consistência de Atterberg obtidos para a argila.

Tabela 2 - Limites de consistência de Atterberg da argila.

\begin{tabular}{l|c|l|l}
\hline Matéria-prima & $\begin{array}{l}\text { Limite de Liquidez } \\
(\%)\end{array}$ & $\begin{array}{l}\text { Limite de } \\
\text { Plasticidade (\%) }\end{array}$ & $\begin{array}{l}\text { Índice de plasticidade } \\
(\%)\end{array}$ \\
\hline & 31,6 & 20,2 & 11,4 \\
\hline
\end{tabular}

Fonte: Autor (2021).

O resultado do limite de plasticidade correspondeu a 31,6\%. Isso demonstra queo solo apresenta boa plasticidade por possuir uma quantidade suficiente de finos (argila + silte) para garantir à mistura a capacidade de ser moldado no momento da fabricação do tijolo ecológico.

Para a moldagem de tijolos ecológicos, recomenda-se segundo a NBR 10833/12 que o limite de liquidez seja menor ou igual a $45 \%$ e que o limite de plasticidade seja menor ou igual a 18\%. A amostra do solo apresenta limite de liquidez de $31 \%$ e um limite de plasticidade de 20,2\%, resultando em um índice de plasticidade de 11,4\%, sendo assim, o solo estudado é apropriado para a fabricação de tijolo solo cimento.

\subsection{FRX da argila}

Conforme verificado na análise (Tabela 3), não há presença de $\mathrm{CaO}$, pois é um óxido pernicioso, quando encontrado em quantidade significativa, e dependendo de sua granulometria, pois em locais com umidade elevada pode 
trazer danos ao bloco em função da hidratação do óxido, que se expande na presença de água, podendo ocasionar fissuras no mesmo, reduzindo a resistência mecânica. Na mostra também foram encontradas como composições majoritários óxido de silício $\left(\mathrm{SiO}_{2}\right) 57,17 \%$ e o óxido de alumínio $\left(\mathrm{Al}_{2} \mathrm{O}_{3}\right)$ 29,85\%, que estão associados aos componentes argilominerais. A hematita $\left(\mathrm{Fe}_{2} \mathrm{O}_{3}\right) 11,19 \%$ como a terceira maior concentração na argila, este componente confere a coloração avermelhada da argila. Os resultados estão apresentados na Tabela 1.

Tabela 3 - Análise Química por Fluorescência de Raios-X da argila.

\begin{tabular}{ll}
\hline Elemento & Concentração (\%) \\
\hline $\mathrm{SiO} 2$ & 57,17 \\
\hline $\mathrm{Fe} 2 \mathrm{O} 3$ & 11,19 \\
\hline $\mathrm{A} 12 \mathrm{O} 3$ & 29,85 \\
\hline $\mathrm{TiO} 2$ & 0,86 \\
\hline $\mathrm{K} 2 \mathrm{O}$ & 0,93 \\
\hline
\end{tabular}

Fonte: Autor (2021).

A alta concentração de sílica indica que a argila tem potencial para aplicação na produção de tijolo ecológico.

\subsection{Ensaios de Compactação}

Observa-se na Tabela 4 que a adição de PET diminui a umidade ótima, assim a adição do resíduo promove um material mais compacto, promovendo a melhor acomodação das partículas, obtendo o material mais resistente.

Tabela 4 - Resultado do ensaio de compactação.

\begin{tabular}{c|c}
\hline Traço & Umidade Ótima (\%) \\
\hline O\% de adição de PET & 14,20 \\
\hline $20 \%$ de adição de PET & 13,48 \\
\hline $30 \%$ de adição de PET & 13,21 \\
\hline $50 \%$ de adição de PET & 13,01 \\
\hline
\end{tabular}

Fonte: Autor (2021).

\subsection{Absorção de água}

Os resultados obtidos dos 3 corpos de prova para cada traço no teste de absorção de água para determinar a porcentagem em média de absorção de água realizados na UNIFAPI estão descritos na tabela.

Tabela 5 - Absorção média de água aos 28 dias.

\begin{tabular}{l|c|c|c|l}
\hline Composição: & $0 \%$ & $20 \%$ & $30 \%$ & $50 \%$ \\
\hline Absorção de água & $12,65 \%$ & $14,75 \%$ & $10,75 \%$ & $14,13 \%$ \\
\hline
\end{tabular}

Fonte: Autor (2021). 
Os resultados da Tabela 5 para absorção de água demonstraram que os corpos de prova com de adição de PET triturados atenderam os limites estabelecidos pela NBR 8491:2012 no qual, o valor individual não pode ser superior a 22\% e a média de valores não pode ser maior de $20 \%$.

\subsection{Ensaio de resistência à compressão}

As amostras ensaiadas devem estar de acordo com a ABNT NBR 8492/2012, não podendo apresentar média dos valores de resistência à compressão menor do que 2,0 Mpa e nem valor individual inferior a 1,7 Mpa, com idade mínima de sete dias.

O ensaio de resistência a compressão foi realizado em sete tijolos, para cada grupo de formulação (0\%, 20\%, 30\% e $50 \%$ ) de adição de PET triturados. A Tabela 6 abaixo, mostram os valores médios de resistência à compressão simples.

Tabela 6 - Resultados médios dos ensaios de resistência a compressão.

\begin{tabular}{|c|c|c|c|}
\hline Tijolo ecológico & 7 DIAS (Mpa) & 14 DIAS(Mpa) & 28 DIAS (Mpa) \\
\hline $\begin{array}{l}0 \% \text { de } \text { PET } \\
\text { triturado }\end{array}$ & 1,80 & 1,84 & 1,89 \\
\hline $\begin{array}{l}20 \% \text { de PET } \\
\text { triturado }\end{array}$ & 1,82 & 2,04 & 2,24 \\
\hline $\begin{array}{l}30 \% \text { de } \text { PET } \\
\text { triturado }\end{array}$ & 1,35 & 148 & 157 \\
\hline $\begin{array}{l}50 \% \text { de } \text { PET } \\
\text { triturado }\end{array}$ & 1,39 & 1,42 & 1,53 \\
\hline
\end{tabular}

Fonte: Autor (2021).

Conforme mostra a tabela 6 o percentual de $20 \%$ de adição de PET triturados apresentou um melhor resultado, visto que, as outras amostras também atingiram valores menores de $2 \mathrm{Mpa}$ em média e enquadraram dentro dos parâmetros exigidos pela NBR 8491:2012. Desta forma, considera-se que a utilização de PET triturados como agregado para o tijolo ecológico é uma alternativa viável, pois apresenta resistência exigida pela NBR 8491/2012 e se apresenta como uma forma de economia e de reciclagem de resíduos que seriam descartados e poluiriam o meio ambiente.

\section{Conclusão}

O tijolo ecológico ou solo-cimento com adição de PET atendeu as normas na ABNT de resistência a compressão e absorção de água. A adição de PET possibilitou condições técnicas para a produção do tijolo ecológico, contribui para reduzir o volume de garrafas no meio ambiente. Após a finalização deste trabalho chegou-se à conclusão de que a formulação ideal é a adição de $20 \%$ PET triturados ao tijolo ecológico. Portanto os tijolos produzidos com adição PET triturados mostraram-se que atendem os requisitos normativos e corroboram para a sustentabilidade, pois transformam materiais descartáveis novos artefatos para construção civil.

\section{Sugestões para trabalhos futuros}

Realizar um estudo da viabilidade econômica do uso de tijolo ecológico ou solo-cimento em comparação com alvenaria convencional; 
Considerando variações ocorridas em alguns testes e medições, sugerem-se diferentes condições de cura e armazenamento;

Estudar o efeito de outros tipos de cimento na estabilização de solos com a adição de PET;

\section{Referências}

ABNT. (2012). NBR 8492- Tijolo de solo-cimento — Análise dimensional, determinação da resistência à compressão e da absorção de água — Método de ensaio.

ABNT. (2012). NBR 10833- Fabricação de tijolo e bloco de solo-cimento com utilização de prensa manual ou hidráulica — Procedimento.

ABNT. (2012). NBR 8491- Tijolo de solo-cimento - Requisitos.

ABRELPE (2013). Associação Brasileira das Empresas de Limpeza Pública e Resíduos Especiais, Panorama de resíduos sólidos no Brasil, $11^{a}$ ed.

ABIPET (2011). ASSOCIAÇÃO BRASILEIRA DA INDÚSTRIA DO PET. $9^{\circ}$ Censo da Reciclagem de PET no Brasil. Disponível em: Acesso: 23 de março. 2016.

Azevedo, G. O. D. (2011). Por menos Lixo: a minimização dos resíduos sólidos urbanos na cidade do Salvador/Bahia. Dissertação (Mestrado) Universidade Federal da Bahia. Escola Politécnicas.

Biobloc. (2015). Origem do Tijolo Ecológico - Um pouco de História. http://biobloctijolosecologicos.blogspot.com/p/blogpage.html\#: ;:text=Ele\%20surgiu\%20atrav\%C3\%A9s\%20de\%20um,conchas\%20de\%20mariscos\%20e\%20trituravam.

Carvalho, R. S. S. (2019). Estudo da viabilidade da utilização da fibra de coco babaçu em formulações de tijolo solo-cimento. Dissertação (Mestrado) Instituto Federal de Educação, Ciência e Tecnologia do Piauí, Piauí.

Dantas, V. B. (2015). Desenvolvimento de blocos de solo cimento utilizando argissolo com incorporação de material armazenador de calor por mudança de fase (MMFs). Tese de Doutorado. Universidade Federal do Rio Grande do Norte.

Frigione, M. (2010). Recycling of PET bottles as fine aggregate in concrete. Waste Management, 30(11), 1101-1106.

Grande, F. M. (2003). Fabricação de tijolos modulares de solo-cimento por prensagem manual com e sem adição de sílica ativa. Dissertação (Mestrado em Arquitetura) São Carlos: Escola de Engenharia de São Carlos Universidade de São Paulo, 165 p.

Gregorio, L. T. D. (2012). Manual de fabricação de tijolos de solo-cimento. Cachoeira Paulista: RJ.

Marconi, M. D. A., \& Lakatos, E. M. (2016). Técnicas de pesquisa: planejamento e execução de pesquisas, amostragens e técnicas de pesquisas, elaboração, análise e interpretação de dados. ( $3^{\mathrm{a}}$.ed.): Atlas.

Mazzeo, G., \& Mazzeo, F. (2003). Fabricação de tijolos modulares de solo cimento por prensagem manual com e sem a adição de sílica ativa. Dissertação de Mestrado em Arquitetura. EESC - Escola de Engenharia de São Carlos, São Carlos.

Moreira, M. C. (2013). Dados e Informações sobre resíduos sólidos urbanos no Brasil. Dissertação (Mestrado) - Escola Nacional de Saúde Pública Sergio Arouca, Rio de Janeiro.

Nascimento, T. C. N. (2011). A natureza dos materiais lateríticos entre Porto Velho e Morrinhos: Relação morfológica e aplicação. Dissertação (Mestrado em Geografia). Programa de Pós- Graduação- Mestrado em Geografia da Fundação Universidade Federal de Rondônia (UNIR) 79p. Porto Velho.

Pecoriello, L. A. (2003). Recomendações práticas para uso do tijolo furado de solo- cimento na produção de alvenaria. Dissertação (Mestrado Profissional em Habitação) São Paulo: Instituto de Pesquisas Tecnológicas, São Paulo, 75 p.

Pinto, C. S. (1998). Propriedades dos solos. In: Fundações: teoria e prática. São Paulo: PINI.

Weber, E., Campos, R. F. F., \& Borga, T. (2017). Análise da eficiência do tijolo ecológico solo-cimento na construção civil. Ignis, Caçador, 6(2), 18-34, maio/ago.

Pisani, M. J. (2005). Um material de construção de baixo impacto ambiental: o tijolo de solo cimento. São Paulo: Sinergia.

Vieira, A., Cechinel, B., Deghenhard, C., Magnus, D., Holthausen, R., Tassi, R., Modesto, C., Noni J., A., \& Cargnin, M. (2007). Estudo do Processo de Obtenção e Caracterização de Tijolos Solo-Cimento. Cerâmica Industrial, 12(6), 47-50. 